\title{
HIERARQUIAS RACIAIS DETERMINAM RELAÇÕES INTERCULTURAIS ENTRE NEGRAS/NEGROS E QUILOMBOLAS E NÃO NEGROS NO SERTÃO DO SÃO FRANCISCO
}

Márcia Guena dos Santos ${ }^{73}$

\section{Resumo}

Este artigo tem por objetivo contribuir com as discussões sobre as trocas/relações interculturais estabelecidas entre negras/negros, especialmente as/os quilombolas, e a população não negra da região do submédio São Francisco, tendo como ponto de partida conceitual as hierarquias raciais estabelecidas no Brasil, na construção de um país racista e excludente. Para isso partirmos das experiências e reflexões nas áreas de pesquisa e extensão desenvolvidas até agora por dois projetos: o projeto de pesquisa Perfil fotoetnográfico das populações quilombolas do submédio são Francisco: identidades em movimento, desenvolvido desde 2011; e projeto de extensão Articulação Quilombola, desenvolvido desde 2013, envolvendo várias instituições da região e comunidades quilombolas.

Palavras-chave: Hierarquias raciais. Interculturalidade. Quilombolas. Negras e negros.

\section{GERARCHIE RAZZIALI DETERMINANO LE RELAZIONI INTERCULTURALI TRA NERE / NERI E QUILOMBOLAS E NON NERI NEL SERTÃO DEL SÃO FRANCISCO}

\begin{abstract}
Sintesi
Questo articolo si propone l'obiettivo di contribuire alle discussioni sugli scambi/relazioni interculturali stabilite tra nere/neri, in particolare le e i quilombolas, e la popolazione non nera della regione del submédio São Francisco, avendo come punto di partenza concettuale le gerarchie razziali stabilite in Brasile, nella costruzione di un paese razzista ed escludente. Per questo partiamo dalle esperienze e riflessioni nelle aree di ricerca e terza missione accademica sviluppate finora da due progetti: il progetto di ricerca 'Profilo foto-etnografico delle popolazioni di quilombolas del submédio São Francisco: identità in movimento', sviluppato a partire dal 2011, e il progetto di terza missione 'Articolazione Quilombola', sviluppato dal 2013, che coinvolge varie istituzioni della regione e comunità quilombolas.
\end{abstract}

Parole chiave: Gerarchie razziali. Interculturalità. Quilombolas. Nere e neri.

\footnotetext{
${ }^{73}$ Doutora em História pela Universidade Complutense de Madrid, mestre em Integração na América Latina e Jornalista pela Universidade de São Paulo (USP); professora do curso de Jornalismo da Universidade do Estado da Bahia (UNEB); coordenadora do grupo de Pesquisa Rhecados - Hierarquizações raciais, Comunicação e Direitos Humanos. Pesquisa atualmente as comunidades quilombolas e Povos de Terreiro no Vale do São Francisco.
} 


\title{
RACIAL HIERARCHIES DETERMINE THE INTERCULTURAL RELATIONS BETWEEN BLACKS/BLACK PEOPLE AND QUILOMBOLAS AND NOT BLACKS IN THE SERTÃO OF THE SÃO FRANCISCO
}

\begin{abstract}
This article aims to contribute to the discussions on the intercultural exchanges / relations established between black people, in particular the quilombolas, and the non-black population of the region of the submédio São Francisco, having as a conceptual starting point the established racial hierarchies in Brazil, in the construction of a racist and exclusionary country. For this reason we start from the experiences and reflections in the research and academic third mission areas developed until now by two projects: the research project 'Photo-ethnographic profile of the populations of quilombolas of the submédio São Francisco: identity in movement', developed from 2011, and the third mission project 'Articulation Quilombola', developed since 2013, which involves various institutions of the region and quilombolas communities.
\end{abstract}

Keywords: Racial hierarchies. Interculturalism. Quilombolas. Black people.

\section{Introdução}

O Brasil é um país majoritariamente negro, com 118,6 milhões de pessoas que se autodeclaram negras (preta e pardas), ou seja 56\% dos 210, 5 milhões de habitantes - e 89,9 milhões de pessoas brancas - de acordo com dados projetados pela Pesquisa Nacional por Amostra de Domicílios Contínua (PNAD), para o primeiro trimestre de 2020 (IBGE, 2020a). Apesar de ser majoritária, a população negra está submetida às piores condições de acesso a bens de consumo e de cidadania. As pesquisas acadêmicas e os meios de comunicação, de diferentes alinhamentos editoriais têm denunciado e chamado atenção para estas estatísticas há anos e de forma sistemática, inclusive vários organismos internacionais, como a Organização das Nações Unidos (ONU), estampando várias campanhas em suas páginas como Vidas Negras Importam (ONU, 2020).

Segundo o Atlas da Violência de 2019 (IPEA, 2019, p.49), que traz dados de 2017, “75,\% das vítimas de homicídios foram indivíduos negros (...) sendo que a taxa de homicídios por 100 mil negros foi de 43,1, ao passo que a taxa de não negros (brancos, amarelos e indígenas) foi de 16,0 ”. Um dos dados mais chocantes refere-se ao genocídio da juventude negra, entre 15 e 29 anos:

De acordo com dados do Sistema de Informações sobre Mortalidade (SIM), do Ministério da Saúde, foram registradas 255 mil mortes de pessoas negras por assassinato nos seis anos analisados. Entre os jovens 
brancos de 15 a 29 anos, a taxa era de 34 mortes para cada 100 mil habitantes em 2017, último ano com dados de mortes disponíveis no DataSus. Entre os pretos e pardos, eram 98,5 assassinatos a cada 100 mil habitantes. Fazendo o recorte apenas dos homens negros nessa faixa etária, a taxa de homicídio sobe para 185. Para as mulheres jovens, a taxa é de 5,2 entre as brancas e 10,1 para as pretas e pardas." (NITAHARA, 2019)

O feminicídio também vitimiza preferencialmente as mulheres negras, como aponta do Atlas da Violência (IpEA), 2019. Foram registrados 4.936 assassinatos de mulheres em 2017, uma média de 13 homicídios por dia, significando o maior número da década. Porém, quando cruzamos com o aspecto raça:

Enquanto a taxa de homicídios de mulheres não negras teve crescimento de 4,5\% entre 2007 e 2017, a taxa de homicídios de mulheres negras cresceu 29,9\%. Em números absolutos a diferença é ainda mais brutal, já que entre não negras o crescimento é de $1,7 \%$ e entre mulheres negras de $60,5 \%$. A desigualdade racial pode ser vista também quando verificamos a proporção de mulheres negras entre as vítimas da violência letal: $66 \%$ de todas as mulheres assassinadas no país em 2017. O crescimento muito superior da violência letal entre mulheres negras em comparação com as não negras evidencia a enorme dificuldade que o Estado brasileiro tem de garantir a universalidade de suas políticas públicas (IPEA E FBSP 2019, p 38-39).

Não iremos mais longe na descrição das estatísticas porque nosso objetivo, ao trazer alguns números, é mostrar a concretude do racismo e suas sequelas e que, na discussão sobre relações entre culturas no Brasil é indispensável considerá-lo, pois ele estrutura nossa sociedade e todas as outras da diáspora negra. Modifica, limita e reduz a relação que temos com o mundo e com a cultura. A liberdade do corpo e do pensamento negros e todas as suas possibilidades são estreitadas pela violência racial e todas as suas formas de expressão.

Na região do Sertão do São Francisco não é diferente, ainda que tenha suas especificidades. Nas cidades onde temos desenvolvido pesquisas junto às comunidades tradicionais (quilombolas e povos de terreiro), Juazeiro, na Bahia, e Petrolina, em Pernambuco, a população negra é majoritária, $75 \%$ e $67 \%$ respectivamente, quando consideramos a soma de pretos e pardos, de acordo com a tipologia adotada pelo Censo de 2010 aplicado pelo IBGE (2020b). Assim, neste artigo discutiremos os conceitos de hierarquias raciais, corpo e interculturalidade, para logo depois perfilar as comunidades quilombolas com as quais trabalhamos e, por fim, a forma como se relacionam com outras culturas, ou, mais particularmente as culturas hegemônicas. 


\section{Hierarquias raciais}

A sociedade brasileira foi organizada sob a base de várias estruturas coloniais que não se desmontaram com o estabelecimento da república. As elites que ocuparam o poder no Brasil Império e no Brasil República, os brancos crioulos ou mestiços claros, como denomina Angela Fiqueiredo (2012), reproduziram as estruturas de dominação coloniais, fazendo com que a maioria da população negra (pretos e pardos) e indígena não conseguisse atingir lugares de privilégio ou mesmo acessar os marcos da cidadania em um país que ia se moldando às custas de várias exclusões violentas. "A luta pela independência dos brancos crioulos (poderíamos dizer mestiços claros), nunca descolonizou a hierarquia étnico-racial do poder político, econômico e social construído durante o colonialismo europeu nas Américas" (FIGUEIREDO, 2012, p. 91). Assim, Figueiredo conclui que dois processos marcaram a colonialidade no Brasil: 1. "Relações de poder na divisão internacional do trabalho em âmbito global com a periferia explorada; 2. As relações de poder e de classe" (FIGUEIREDO, 2012, p. 92). Esses processos aconteceram mediante ações institucionalizadas do Estado, como a restrição do acesso ao trabalho e à educação, o não acesso à terra na saída da escravidão, a política de branqueamento e, somado a tudo isso, o código penal que encarcerou levas de população negra pelo crime de vadiagem, entre outros.

A consequência disso é uma sociedade hierarquizada a partir da raça/cor/gênero, com a peculiaridade do racismo no Brasil, que se estabelece a partir do colorismo da população: os pretos mais claros têm mais chance de colocação na sociedade do que os mais escuros. Esses aspectos garantem a formação de uma elite embranquecida tanto física como ideologicamente, estabelecendo uma pirâmide racial, em cuja base estão os mais escuros e, no topo, os mais claros em termos de Ascenção social e acesso a bens de toda natureza, inclusive culturais. Assim, todos os aspectos da reprodução da vida e da cultura relacionados aqueles que estão na base da pirâmide são desconsiderados e desprezados como valores menores. Esta máxima vale para todos os aspectos da vida, a exemplo da cultura, da estética, das artes e da construção de epistemologias. 


\section{Corpos vigiados}

Sob esta condição hierárquica os corpos negros circulam e sobrevivem ao racismo. Porém houve muita luta e resistência, desde a chegada dos primeiros africanos, o que tem garantido alguns avanços, principalmente legais e especialmente a partir da constituição do 1988. As políticas de ações afirmativas voltadas para a população negra garantiram, por exemplo, o ingresso no ensino superior, permitindo uma distribuição mais equitativa de vagas nas universidades públicas. Avanços esses ameaçados pela ascensão do governo conservador, em janeiro de 2019. A exemplo da redução do número de certificações de comunidades quilombolas e o esvaziamento das funções da Fundação Cultural palmares, impulsionadora das conquistas institucionais dessa população tradicional. Avançávamos em um espaço possível de negociação das liberdades.

Porém, a vigilância sobre os corpos negros ainda é grande e impede que as trocas e relações culturais sejam horizontais. Enquanto os brancos de algumas nacionalidades hegemônicas circulam livremente pelo mundo, pelos aeroportos, entram e saem das grandes redes de lojas, os corpos negros são barrados e precisam atravessar essas barreiras. Alguns não atravessam.

É o corpo do jovem homem negro que é visto como epítome dessa promessa de selvageria, de poder físico ilimitado e de erotismo incontrolável. Era esse corpo nego mais "desejado" para o trabalho na escravidão, e é esse corpo o mais representado na cultura popular contemporânea como o corpo a ser vigiado, imitado, desejado, possuído. Em vez de um sinal de prazer na vida diária, fora reino do consumo, o corpo do jovem negro é representado mais graficamente como o corpo com dor (HOOKS, 2019, p.86)

Para as populações negras que residem na zona rural as limitações de circulação ainda são maiores, determinadas pela falta de políticas públicas de acesso a bens e serviço, como por exemplo o transporte. Estão sujeitas, dessa forma, a um certo confinamento que não passa apenas pela dificuldade de mobilidade, mas pelos preconceitos e barreiras raciais que encontram no confronto com a cultura urbana. Esta o estigmatiza e o impõe um lugar único e determinado, sem direito a fala e expansão corporal. Para entender em que consiste este isolamento territorial, é importante pensar no conceito de racismo ambiental. 


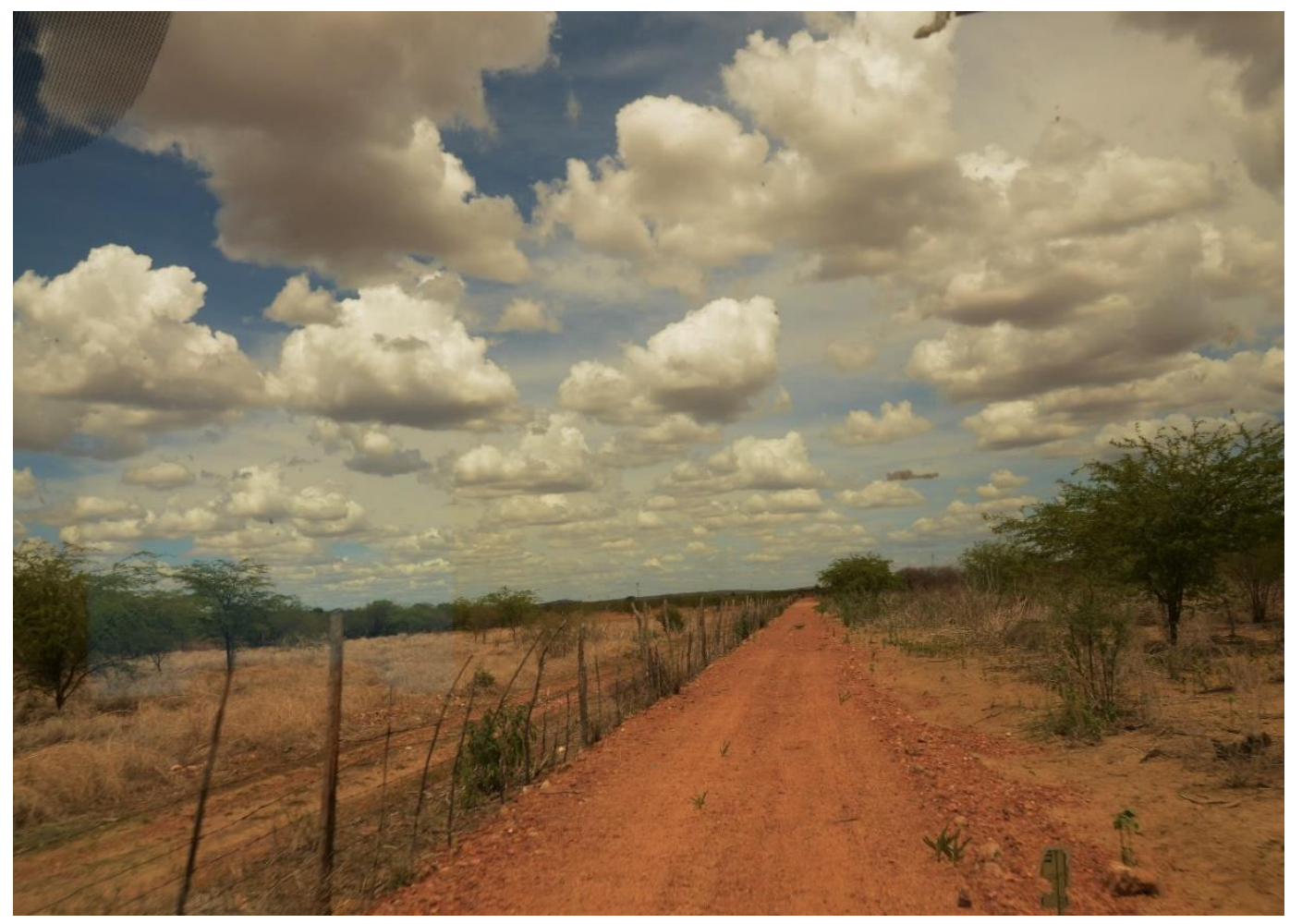

Figura 1- Entrada da comunidade do Alagadiço

Este conceito nos ajuda a pensar sobre os territórios ocupados pelas negras e negros no Brasil e como eles também determinam a sua inserção social, sendo fatores de exclusão. As sociedades e os governos não intervêm para melhora das condições ambientais das áreas ocupadas pela população negra e pobre, mantendo condições precárias de vida de determinado grupo de pessoas, em detrimento de áreas privilegiadas, quase sempre das elites dominantes. Esse conjunto de ausências, ou seja falta de acesso a equipamentos urbanos básicos, como postos de saúde, escola, saneamento, transporte, áreas de lazer, se configura no racismo ambiental. Assim, ocorre a naturalização da inferioridade de determinada parcela da população afetada, incluindo "negros, índios, migrantes, extrativistas, pescadores, trabalhadores pobres, que sofrem os impactos negativos do crescimento econômico e a quem é imputado o sacrifício em prol de um benefício para os demais" (HERCULANO, 2006, p. 11).

É dentro deste contexto que se insere o corpo quilombola, transversalizado por várias exclusões, três delas predominantes: o ser negro, o ser rural, o ser pobre. No caso das mulheres ainda se sobrepõe o ser mulher negra e quilombola. Mas vamos falar neste 
artigo especificamente das comunidades quilombolas dos municípios de Juazeiro e Casa Nova, localizadas no extremo norte da Bahia, onde se concentram os projetos de pesquisa e extensão que desenvolvemos na região há oito anos. Para além de reflexões sistemáticas, trazemos reflexões baseadas em uma longa vivência, baseada em uma metodologia militante, de defesa intransigente dos direitos das populações afro-indígenas da região. Ou seja, não aplicamos aqui uma métodos e técnicas de pesquisas nos distanciados do contexto. Nos imbricamos nele, tentando apresentar algumas saídas. Aí reside o seu aspecto militante.

No Brasil existem hoje 3.386 comunidades quilombolas identificadas pela Fundação Cultural Palmares (FCP) e 2.444 comunidades quilombolas certificadas, de acordo com dados da própria entidade ${ }^{74}$. No município de Juazeiro (BA) há o registro de 14 comunidades quilombolas, de acordo com levantamento do extinto Ministério do Desenvolvimento Agrário (MDA). Porém, durante a pesquisa realizada pelo projeto "Perfil Fotoetnográfico das Populações Quilombolas do Submédio São Francisco: identidades em movimento", este número é maior, pois há grupos menores ainda não catalogados. Apesar desse número expressivo, apenas três delas, Rodeadouro, Alagadiço e Barrinha da Conceição são certificadas pela FCP. Esta certificação foi obtida após a intervenção do projeto citado, o qual priorizou, em uma de suas etapas, realizar ações de sensibilização com relação aos direitos quilombolas, como palestras, cursos e debates. Isso significa dizer que não houve qualquer intervenção do Estado no sentido de expandir uma política pública já institucionalizada, desde a Constituição de 1988 e da formação da Fundação Cultural Palmares, no mesmo ano. Situação similar acontece em Casa Nova, que teve a sua primeira comunidade quilombola certificada em 2016, Sitio Lagoinha. Ou seja, estas certificações só acontecem a partir de 2016, 28 anos após o direito ter sido estabelecido, estas comunidades recebem suas certificações da FCP e passam a acessar direitos e recursos públicos enquanto quilombolas.

\footnotetext{
${ }^{74}$ Para serem reconhecidas pelo Estado brasileiro como quilombolas, as comunidades negras devem passar por dois processos: o primeiro é a certificação como quilombolas, solicitada pelas comunidades à Fundação Cultural Palmares (FCP), órgão criado para essa finalidade; o segundo processo se refere à titulação da terra, documento que deve ser solicitado ao Instituto Nacional de Colonização e Reforma Agrária (INCRA) através da abertura de um processo formal. As certificações são processo relativamente rápidos, porém foram praticamente estancados em 2019, durante o governo do presidente Jair Bolsonaro, cujo discurso e práticas são contrários ao reconhecimento e direitos das comunidades tradicionais. Os processos de titulação nunca foram estabelecidos a contento. Das 2444 comunidades certificadas, menos de 300 estão tituladas. Os processos são morosos, levam cerca de 10 anos e o INCRA nunca teve um corpo de profissionais capaz de acelerar essas titulações.
} 
As dificuldades enfrentadas pelas comunidades quilombolas de Juazeiro e Casa Nova repercutem em seus modos de vida, levando ao empobrecimento e à falta de perspectiva para os mais jovens. Porém, o mais grave é a perda da memória ancestral e de suas tradições, pois estão no território há mais de 200 anos, como podemos levantar através dos depoimentos orais ${ }^{75}$. Assim, o acesso às políticas públicas e às políticas afirmativas tem um papel fundamental de permitir um retorno a essa ancestralidade, a compreensão e valorização de suas culturas e identidades, aspectos extremamente vilipendiados pelos sucessivos processos de exclusão, desde a invasão dos colonizadores portugueses, passando pelo coronelismo marcante no Nordeste e chegando até o expurgo modernizante e excludente do agronegócio.

\section{Expressões da cultura quilombola e as trocas desiguais}

As expressões da cultura quilombola e de suas heranças afro-indígenas estão presentes no dia-a-dia das comunidades, compreendendo a cultura de forma ampla, a partir de suas práticas sociais e relação com o mundo. Estão nas práticas ancestrais de lida com a terra e dos produtos que dela extraem para vida. Um dos exemplos é o cultivo ancestral da mandioca e os subprodutos obtidos artesanalmente, nas casas de farinha, mas que garantem o sustento e reprodução da vida. Estão nos cuidados com a saúde, através da utilização da ervas medicinais, rezas e outras práticas tradicionais, hoje incorporadas pela medicina ocidental e denominadas de práticas integrativas de saúde, um verdadeiro reconhecimento da sabedoria ancestral. Estão nas formas de tratamento dos mais velhos, ainda recebendo deferência, respeito e consideração, com seus lugares de fala preservados, em certa medida. Está na religiosidade sincrética, que traz na frente a herança da catequização católica na região, mas guarda aspectos das religiosidades africana e indígena importantes, com destaque para o respeito à mediunidade e às entidades ainda lembradas e cultuadas em algumas regiões: preto-veio, orixás e caboclos. As expressões da cultura também se dão nas práticas mais visibilizadas, que sejam a música e a dança, como o samba-de-veio, o samba de lata e as rodas de São Gonçalo, tão comuns na região e fruto de uma herança sincrética. Do samba-de-veio participavam apenas os mais velhos, nas suas formações iniciais, e um tamborete de couro era a

\footnotetext{
75 No blog www.quilombosesertoes.blogspot.com estão os artigos publicados pela pesquisa "perfil Fotoetnográfico das populações quilombolas do submédio São Francisco: identidades em movimento", onde estão registradas várias entrevistas realizadas de 2012 a 2018.
} 
principal percussão, ao som do qual as mulheres dançavam com saias rodadas. Hoje as crianças e jovens já participam dessa festa. O samba-de-lata, como o nome já faz referência, é tocado em uma lata e as mulheres dançam também com saias rodadas, ao som de canções que lembram as histórias e vivências das comunidades. Já a Roda de São Gonçalo é uma manifestação sincrética, de predominância católica. Aquele que patrocina a roda, está pagando uma promessa para São Gonçalo. Então, ao longo do dia o fiel oferece refeições a todos os presentes e são realizadas várias rodadas de danças tradicionais específicas (as rodas), com características distintas, de acordo com a finalidade e a localidade ${ }^{76}$.

Na comunidade quilombola Sítio Lagoinha, o cultivo da mandioca e as casas de farinha marcam o ritmo da lida com a terra e as formas ancestrais do trabalho. O São Gonçalo marca todas as festas, seja como rito religioso ou como confraternização, sob a liderança dos mais velhos e a participação de jovens e crianças. Na comunidade do Rodeadouro o Samba de Veio, um estilo que de samba cantado e dançado por mulheres e homens, com um pequeno tambor como percussão e uma viola. As mais velhas conduzem, com a participação de jovens. Na comunidade de Barrinha da Conceição, os cânticos da jurema ainda são lembrados por Dona Roberta, uma das moradoras mais velhas. No Alagadiço muitas práticas culturais estão se perdendo, permanecendo apenas lembranças da lida tradicional com a terra. Com exceção do Sitio Lagoinha, essas são comunidades vizinhas, com laços de consanguinidade, localizadas na beira do São Francisco, próximas uma da outra.

De cada uma dessas expressões poderíamos elaborar uma reflexão particular, que remeteria a uma ancestralidade profunda e híbrida. Porém, esse não é o objetivo. O que se quer é apontar que as comunidades quilombolas da região, mesmo diante de opressões permanentes, mantem laços como suas culturas ancestrais e resistem ao desmantelamento. Deste modo, pensar em interculturalidade é pensar também nessas opressões sucessivas. Portanto a relação com a cultura hegemônica é desigual e não harmônica como à primeira vista possa revelar essa palavra interculturalidade.

Durante esses anos um aspecto ficou muito evidente na região investigada. A cultura negra viva em algumas dessas comunidades, através de manifestações culturais e práticas cotidianas, ou mesmo aquela subjacente na memória de seus moradores mantem uma relação de inferioridade em relação à cultura urbana vigente, originada nas

\footnotetext{
${ }^{76}$ Essas informações foram coletadas ao longo da pesquisa nas comunidades quilombolas do Rodeadouro, Tijuaçu e Sítio Lagoinha.
} 
práticas das elites urbanas regionais e nacionais e nas esferas preponderantes de consumo, não inclusa nas opções culturais urbanas. Desse modo, tudo que é de origem negra, rural quilombola passa a ocupar um espaço restrito e folclorizado, vinculando-se a datas específicas, como o dia da abolição da escravidão, o dia da consciência negra, o dia do folclore ou o dia de combate ao racismo. Assim, as práticas culturais negras não passam a ser inclusas em um calendário cotidiano cultural dos vários segmentos populacionais dos espaços investigados, ocupando igualitariamente os espaços, resultando assim em uma relação intercultural desigual.

Por outro lado, as opções de cultura e lazer dominantes e integrantes da agenda urbana na cidade de Juazeiro, que incluem cinema, teatro, feiras, shows, as práticas de aquisição de bens de consumo, adquirem uma valoração superior às práticas oriundas das populações negras rurais quilombolas. Esse é o aspecto central a ser abordado nesse artigo: a desigualdade nas trocas entre o grupo em questão e a cultura dominante local na região. (SANTOS, 2016, p.35)

É importante localizar a desigualdade nas relações culturais a partir de uma perspectiva racial e de classe, que subalterniza os grupos em questão e a partir da concepção de Stuart Hall (2015) a respeito do conceito de cultura/identidade. Para o autor, e também para nós, os grupos quilombolas não possuem culturas tradicionais puras, mas são resultado de vários processos de hibridização cultural, a partir dos quais também se pode pensar a interculturalidade. Por tanto não estão imersos em um bolha de tradições, mas em contato permanente com outras culturas, sendo contaminados por elas. Mas esta questão deve ser pensada a partir do conceito de hegemonia, afirma Hall (2015), por tanto de trocas desiguais, e dentro da disputa entre o global e o local.

\section{O significado dos projetos de extensão e as novas trocas culturais}

É este complexo universo de trocas culturais, marcadas pelos aspectos que determinam a subalternização dos povos quilombolas que as universidades e nós entramos, engendrando novas trocas e novas subalternizações e hegemonias. Temos trabalhado há oito anos com comunidades quilombolas em Juazeiro, na perspectiva geral de fazer com que as mesmas, caso desejem, tenho ciência de seus direitos, os reivindiquem perante o Estado e usufruam dos mesmos. Ou seja, uma prática cultural acadêmica pautada nas conquistas do Estado democrático. Para nós uma máxima fundamental e importante. Para as comunidades quilombolas que conhecemos, para as famílias negras das quais nos aproximamos significa uma prática cultural nova, um novo modos operandi na relação com o Estado. Assim, se estabelece uma relação intercultural 
novamente desigual, ainda que com princípios nobres, a qual, portanto, requer cuidado e respeito.

Inicialmente o projeto de pesquisa "Perfil Fotoetnográfico das populações quilombolas do Submédio São Francisco: Identidades em Movimento" realizou uma cartografia das comunidades quilombolas de Juazeiro, conseguindo reunir informações sobre nove territórios, que seguem sistematizados no livro "Quilombos de Juazeiro: entre imagens e histórias". O trabalho se desdobrou a partir das cobranças iniciais de Dona Vinô, principal liderança da comunidade do Alagadiço: "o que vocês nos darão em troca?", questionou sabiamente a liderança.

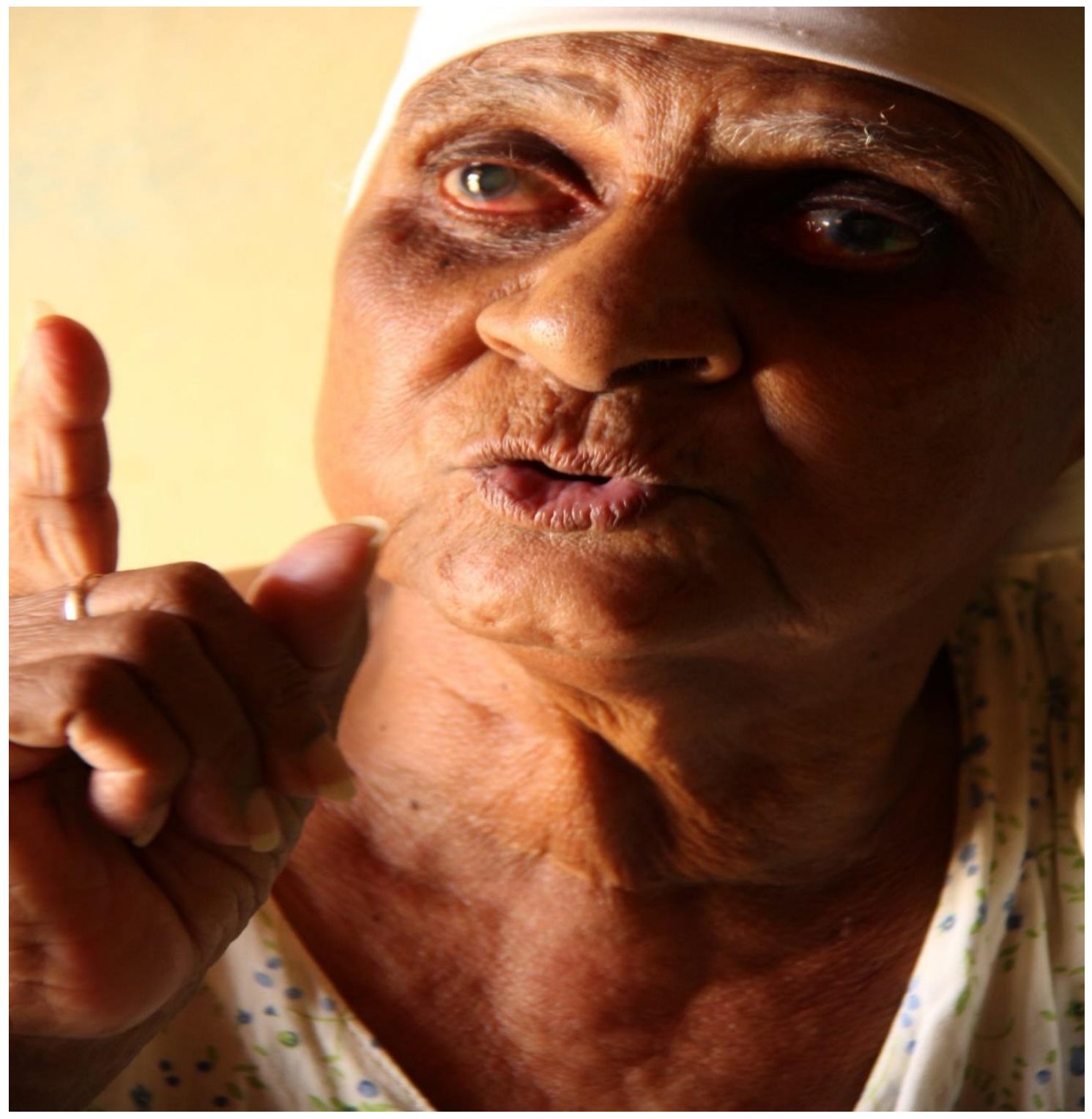

Figura 2 - Alvina dos Santos, conhecida como Dona Vinô, liderança da comunidade quilombola do Alagadiço, uma das responsáveis pelos rumos das pesquisas descritas neste trabalho. 
Esta provocação nos levou a uma pesquisa militante e passamos a organizar palestras sobre direito quilombola, inquirindo as comunidades negras sobre o interesse em acessar esse direito. O processo resultou na certificação de três comunidades quilombolas em Juazeiro (Alagadiço, Rodeadouro e Barrinha da Conceição), com a nossa assessoria. Concomitantemente, o projeto de pesquisa tornou-se um projeto de extensão denominado "Articulação Quilombola”, que reúne hoje várias instituições: órgãos da Prefeitura Municipal de Juazeiro e Casa Nova; Universidade do Vale do São Francisco (Univasf); Coletivo de Assessoria Jurídica Popular Luiz Gama (Cajup), um projeto dos estudantes de direito da UNEB; Movimento Antirracista do Vale (Mave); Conselho Municipal de Promoção da Igualdade Racial (Compir), de Juazeiro; Defensoria Pública da União, com sede em Petrolina. Estas entidades promovem diferentes ações junto às comunidades quilombolas. Abaixo elencamos algumas delas.

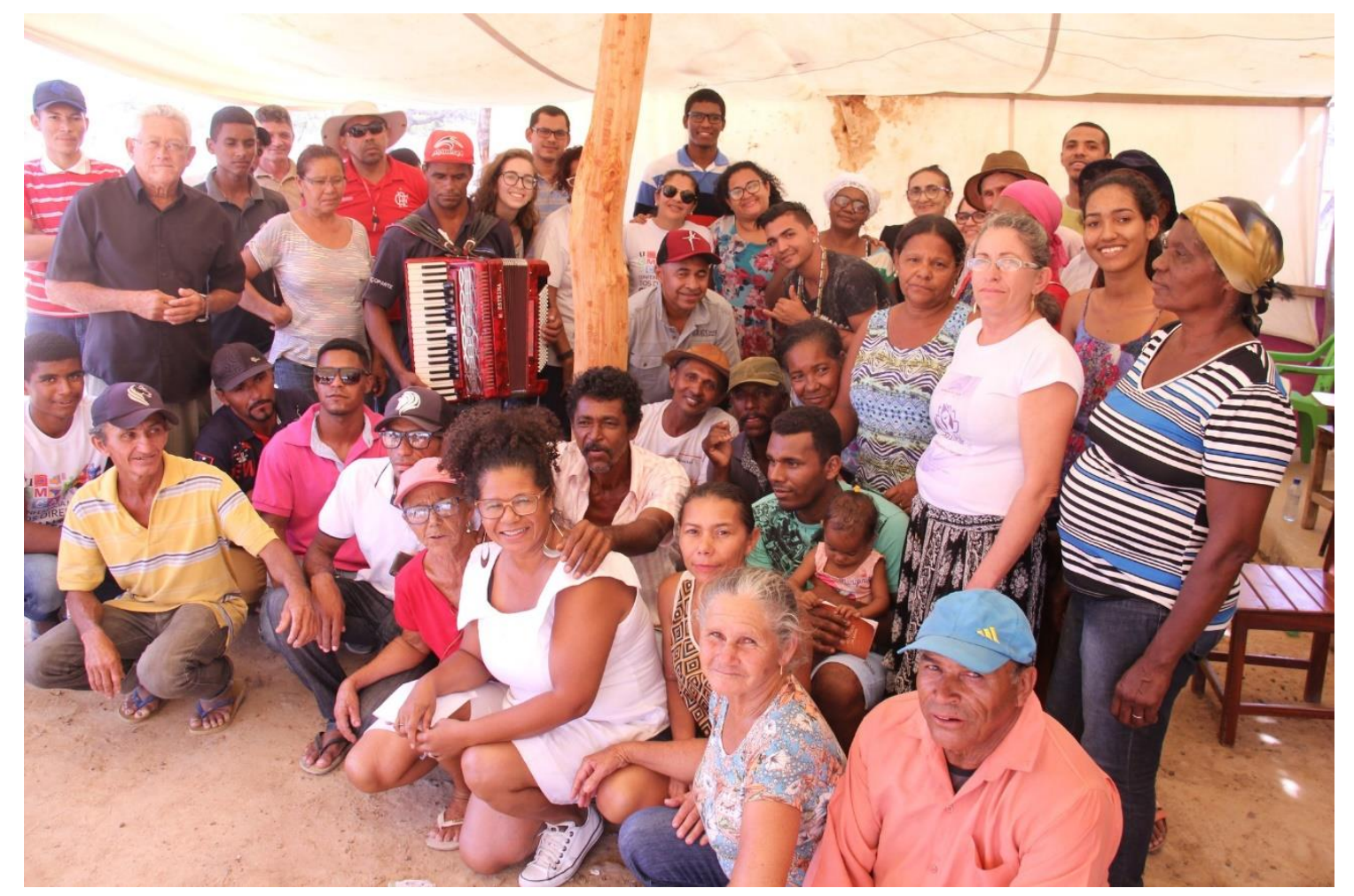

Figura 3- Finalização do Fórum de Igualdade Racial, na comunidade quilombola Sitio Lagoinha, em Casa Nova, Bahia.

A conjunção dessas instituições e entidades, através de um trabalho em rede, tem permitido a realização de diversos projetos em conexões. Dentre os principais está a elaboração e/ou acompanhamento de projetos de geração de renda, na perspectiva de uma 
economia sustentável. Assim, em 2018, duas comunidades conquistaram um projeto do governo do Estado da Bahia, Bahia Produtiva, que gerará renda e perspectiva de fixação na comunidade. O grupo de articulação quilombola tem realizado várias oficinas: de leitura; de estética afro e na área de direito quilombola. O grupo também tem estimulado a participação em eventos políticos ligados aos direitos das comunidades tradicionais. $\mathrm{O}$ Coletivo de Assessoria Jurídica Popular Luiz Gama (Cajup) tem sido um importante apoiador na resolução e acompanhamento jurídico de conflitos. As prefeituras municipais são os principais canais para acesso a algumas políticas públicas voltadas para os quilombolas, começando pela inclusão desses grupos no cadastro único, o que permite a acessar bens e serviços através de uma política específica.

A perspectiva para esses grupos é de conquista de direitos, acesso a bens culturais e de consumo e valorização identitária, ainda que de maneira gradual. Porém, a articulação em rede tem permitido o conhecimento de formas de lidar com essas políticas. Mais do que os benefícios que os projetos estão trazendo, as comunidades estão acessando o Estado e a sua complexidade, conhecendo seus direitos e as formas de reivindicá-los. Identificamos que o principal problema do Estado tem sido não permitir o acesso desses grupos a informações sobre os direitos reivindicados pelos próprios movimentos.

\section{Considerações finais}

Através das reflexões e andanças pelas caatingas distantes onde moram as comunidades negras quilombolas do submédio São Francisco, muitas vezes com dificuldade de acesso a água, a luz elétrica e ao transporte, temos questionado o conceito de interculturalidade, colocando em dúvida a leveza que muitos autores trabalham com esse conceito, sem considerar, muitas vezes, as desigualdades demarcadas pelas diversas formas de racismo e sexismo. Como se o encontro entre culturas fosse sempre uma grande festa, em que os elementos das culturas hegemônicas e não hegemônicas circulassem da mesma forma através dos territórios.

Essas populações carregam, sem dúvida alguma, um conhecimento ancestral sem medida na sua relação com o território, com a cultura e com a vida. Porém, as necessidades de sobrevivência vão dilapidando toda essa riqueza. Os racismos e o patriarcalismo vão se sobrepondo e estabelecendo várias exclusões. São nessas condições que se estabelecem as trocas culturais com os ambientes urbanos que possuem acesso muito mais vantajoso a bens e serviços. O conceito de sistema-mundo, baseado em 
exclusões violentas inauguradas com a colonização, permite entender o porquê essas culturas seguem subalternizadas e relegadas a um lugar desvalorizado frente ao que é produzido pelas elites brancas.

A lógica moderno/colonial exerce uma força contrária às tentativas de emancipação e ruptura com as condições impostas pela branquitude, fazendo alusão às bases do pensamento decolonial desenvolvidas por Grosfogel (2018). Ou seja, a modernidade carrega na alma os marcos dos primeiros anos do terror que representou a tomada do continente, a usurpação e morte das nações indígenas e sequestro homens e mulheres africanos, reduzindo conhecimentos e hierarquizando pessoas. A modernidade não se livra da colonialidade que se perpetua em bases violentas e estabelecem, fatalmente trocas culturais desiguais e igualmente hierarquizadas.

\section{Referências bibliográficas}

CARNEIRO, Sueli. Lélia Gonzales: o feminismo negro no palco da história/ Sueli Carneiro. Brasília: Abravídeo, 2014.

IPEA - Instituto Brasileiro de Pesquisa Aplicadas; FBSP -Fórum Brasileiro de Segurança Pública. Atlas da Violência 2019, p. 49. Brasília: Rio de Janeiro: São Paulo: Instituto de Pesquisa Econômica Aplicada; Fórum Brasileiro de Segurança Pública, 2019. Disponível em:http://www.ipea.gov.br/portal/images/stories/PDFs/relatorio institucional/190605 a tlas_da_violencia_2019.pdf. Acessado em 15 de outubro de 2019.

IBGE - Instituto Brasileiro de Geografia e Estatística. Sistema IBGE de Recuperação Automática - SIDRA. Pesquisa Nacional Por Amostra de Domicílio Contínua Trimestral, 2020a. Tabela 6403. População por cor ou raça. Disponível em: https://sidra.ibge.gov.br/tabela/6403\#resultado. Acessado em 29 de junho de 2020.

.SIDRA. Censo Demográfico. Tabela 3175. População Residente por cor ou raça, segundo situação de domicílio, o sexo e a idade. Disponível em: https://sidra.ibge.gov.br/tabela/3175. Acessado em 29 de junho de 2020. FIGUEIREDO, Angela. Decolonização do pensamento no século XXI. In: FUNDAÇÃO Cultural Palmares (2015). Legislação. Disponível em http://www.palmares.gov.br/wp-content/uploads/2010/11/legis09.pdf, acessado em 15 de dezembro de 2015.

GROSFOGEL, Ramón. Para uma visão decolonial da crise civilizatória e dos paradigmas da esquerda ocidentalizada. In: BERNARDINO-COSTA, Joaze; MALDONADOTORRES, Nelson; GOSFOGEL, Ramon (orgs). Decolonialidade e pensamento afrodiaspórico. Belo Horizonte: Autêntica, 2018.

HALL, Stuart. A identidade cultural na pós-modernidade. Rio de Janeiro: Lamparina, 2015. 
ONU - Organização das Nacões Unidos. Vidas Negras. 2020. Disponível em https://nacoesunidas.org/campanha/vidas-negras/. Acessado em 29 de junho de 2020.

HERCULANO, Selene. Lá como cá: conflito, injustiça e racismo ambiental. I Seminário Cearense contra o Racismo Ambiental. ANAIS..., Fortaleza, 20 a 22 nov. 2006. Disponível em: <http://www.professores.uff.br/seleneherculano/publicacoes/lacomoca.pdf $>$. Acesso em: 28 set. 2015.

HOOKS, bell. Olhares negros, raça e representação. São Paulo, Elefante, 2019.

NITAHARA, Akemi. Negros têm 2,7 mais chances de serem mortos do que brancos. Agencia Brasil, 13/11/2019. Disponível em: https://agenciabrasil.ebc.com.br/geral/noticia/2019-11/negros-ou-pardos-tem-27-maischances-de-serem-mortos-do-que-brancos. Acessado em 30 de junho de 2020.

SANTOS, Márcia Guena. A cultura quilombola e sua presença no espaços urbanos. Studium Educationis, Ano XVII, N.1, fevereiro 2016. Disponível em: https://ojs.pensamultimedia.it/index.php/studium/article/view/2224/2032. Acessado em $\underline{10 / 11 / 2019}$.

SANTOS, Márcia Guena. Quilombos e Sertões: entre imagens e histórias. Juazeiro: Editor individual: Márcia Guena, 2016. 